Pacific Journal of Mathematics

HOMOTOPY INVARIANCE OF CONTRAVARIANT FUNCTORS 


\title{
HOMOTOPY INVARIANCE OF CONTRAVARIANT FUNCTORS ACTING ON SMOOTH MANIFOLDS
}

\author{
BRIAN K. SCHMIDT
}

\begin{abstract}
It is sometimes possible to prove that a functor is homotopy invariant using only a knowledge of the domain and range categories of the functor. It is known, for example, that every covariant or contravariant functor from the category of simplicial complexes (with continuous mappings) to the category of countable groups is homotopy invariant. This result has been extended to covariant, but not contravariant, functors with domain the category of smooth manifolds. In the contravariant case, the proof breaks down because certain mappings are not differentiable. This fault will be corrected in this paper. Among other results, it will be shown that every contravariant functor from the category of smooth manifolds to the category of countable groups is homotopy invariant.
\end{abstract}

The results mentioned above are proved in [4]. As in [4], we will use the word "cofunctor" to mean a contravariant functor. $\mathscr{C}$ will denote any full subcategory of the category of smooth manifolds which contains the real line $\boldsymbol{R}$ and is closed under the operation product-with- $\boldsymbol{R}$. $\mathscr{G}$ will denote any subcategory of the category of sets in which every object is countable. Let $C^{\infty}(\boldsymbol{R}, \boldsymbol{R})$ denote the monoid of smooth mappings from $\boldsymbol{R}$ to $\boldsymbol{R}$ under composition. Let $D$ denote the monoid dual to $C^{\infty}(\boldsymbol{R}, \boldsymbol{R})$. In light of paragraphs 15 and 16 of [4], Theorem 11 of [4] may be restated as follows:

Theorem 2. If $D$ cannot act faithfully on any countable set, then every cofunctor $\Delta: \mathscr{C} \rightarrow \mathscr{G}$ is homotopy invariant.

The revised approach.

3. Suppose that $D$ acts faithfully on a set $B$. We will prove that $B$ is uncountable. Let $I$ denote the closed interval $[0,1]$. For each $x \in I$, let $P_{x}$ be the set of all $p \in D$ such that the following two conditions are satisfied:

4. $w \in(x, 1) \Rightarrow p(w) \in(x, 1)$

5. $w \notin(x, 1) \Rightarrow p(w)=w$.

It is easy to verify that:

6. If $p^{\prime} \in P_{w}, p \in P_{x}$, and $w \leqq x$, then $p p^{\prime} \in P_{w}$.

7. Observe that every subset of $I$ has a greatest lower bound in I. Hence we may define, for each $b \in B$, a number $\lambda(b) \in I$ which is 
the greatest lower bound of $\left\{x \in I \mid p \in P_{x} \Rightarrow p b=b\right\}$.

Theorem 8. Consider $x \in I$ and $b \in B$ with $x \neq \lambda(b)$. Then $\lambda(b)<$ $x \Leftrightarrow p b=b$ for all $p \in P_{x}$.

Proof. $(\Leftrightarrow)$ Obvious. $(\Rightarrow)$ If $\lambda(b)<x$, there exists $w \in I$ such that $\lambda(b) \leqq w<x$ and $p^{\prime} b=b$ for all $p^{\prime} \in P_{w}$. Consider any $p \in P_{x}$. By 6 , we have $p p^{\prime} \in P_{w}$. Hence $p p^{\prime} b=b$, and so $p b=b$.

9. Let $F$ denote the set of all $f \in D$ such that $w \notin(0,1)$ implies $f(w)=w$ and such that $f$ has an inverse in $D$. Recall that the order of composition is reversed in $D$. Given $p \in P_{x}$ and $f \in F$, it is easy to verify that $f^{-1} p f \in P_{f(x)}$. Hence, for fixed $f \in F$, we have a mapping $p \mapsto f^{-1} p f$ from $P_{x}$ to $P_{f(x)}$. This mapping has an inverse, namely $p \mapsto f p f^{-1}$. So:

10. Given $x \in I$ and $f \in F$, a one-to-one correspondence between $P_{x}$ and $P_{f(x)}$ is provided by $p \mapsto f^{-1} p f$.

THEOREM 11. For any $f \in F$ and $b \in B, f^{-1}(\lambda(b))=\lambda(f b)$.

Proof. Consider $x \in I$ such that $x$ is not equal to $f^{-1}(\lambda(b))$ or $\lambda(f b)$. It suffices to prove that $f^{-1}(\lambda(b))<x \Leftrightarrow \lambda(f b)<x$. Our approach is as follows:

$$
\begin{gathered}
f^{-1}(\lambda(b))<x \\
\mathbb{\|}(\mathrm{i}) \\
\lambda(b)<f(x) \\
\prod_{\text {(ii) }} \\
p^{\prime} b=b, \text { for all } p^{\prime} \in P_{f(x)} \\
\prod_{\text {(iii) }} \\
f^{-1} p f b=b, \text { for all } p \in P_{x} \\
\prod_{\text {(iv) }} \\
p f b=f b, \text { for all } p \in P_{x} \\
\mathbb{\|} \text { (v) } \\
\lambda(f b)<x
\end{gathered}
$$

(i) follows from the fact that $f$ and $f^{-1}$ preserve order. Note that since $x \neq f^{-1}(\lambda(b)), f(x) \neq \lambda(b)$. So (ii) follows from Theorem 8. (iii) 
follows from 10. (iv) is obvious, and (v) follows from Theorem 8.

Theorem 11, restated categorically as in [4], asserts that $\lambda$ is a natural transformation.

Theorem 12. There exists $b \in B$ with $0<\lambda(b)<1$.

Proof. There exists $r \in D$ such that $r(1 / 2)=1 / 2$ and $r(w)=3 / 4$ for all $w \in[3 / 4,1]$. Note that $p r=r$ for all $p \in P_{3 / 4}$. Hence, for any $b \in B, p r b=r b$ for all $p \in P_{3 / 4}$. So $\lambda(r b) \leqq 3 / 4$ for any $b \in B$.

There also exists $p^{\prime} \in P_{1 / 4}$ such that $p^{\prime}(1 / 2)=3 / 4$. Since $r\left(p^{\prime}(1 / 2)\right)=$ $3 / 4$ and $r(1 / 2)=1 / 2$, we have $p^{\prime} r \neq r$. Since $D$ acts faithfully on $B$, there exists $b \in B$ such that $p^{\prime} r b \neq r b$. And since $p^{\prime} \in P_{1 / 4}, \lambda(r b) \geqq$ $1 / 4$ for this $b$.

In summary, we have found $b \in B$ such that $1 / 4 \leqq \lambda(r b) \leqq 3 / 4$.

Theorem 13. $\lambda$ maps $B$ onto $(0,1)$.

Proof. By Theorem 12 there exists $b \in B$ with $\lambda(b) \in(0,1)$. Given any $x \in(0,1)$, there exists $f \in F$ such that $f^{-1}(\lambda(b))=x$. Then, by Theorem 11, $\lambda(f b)=x$.

Corollary 14. B is uncountable.

And by Theorem 2:

CoROLlary 15. Every cofunctor $\Delta: \mathscr{C} \rightarrow \mathscr{G}$ is homotopy invariant.

This proves, for example, that every cofunctor from smooth manifolds to countable groups is homotopy invariant.

\section{Categories without $\boldsymbol{R}$.}

16. Until now, we have been assuming that $\boldsymbol{R}$ was an object in $\mathscr{C}$. Hence we cannot at present apply Corollary 15 to the category of compact smooth manifolds. Let us correct this problem. As was noted in paragraphs 15 and 16 of [4], we may use the circle $S^{1}$ to take the place of $\boldsymbol{R}$. Viewing $S^{1}$ as the closed interval [-1,2] with end points identified, we may define $P_{x}$ to be the set of all smooth mappings from $S^{1}$ to $S^{1}$ satisfying 4 and 5 . Likewise, we may replace $R$ by $S^{1}$ in 6 through 15 without problems. So Corollary 15 applies to any full subcategory $\mathscr{C}$ of the category of smooth manifolds which contains $S^{1}$ and is closed under the operation product- 
with- $S^{1}$

\section{Other generalizations.}

17. If we replace the word "smooth" by "continuous" everywhere in this paper, the proofs remain valid. We have spoken only of smooth structures because our results were already established for continuous structures [4]. Likewise, the proofs given here can be applied to functors as well as cofunctors, with only slight modification. Thus neither Top $(I, I)$, Top $(R, R)$, Top $\left(S^{1}, S^{1}\right), C^{\infty}(R, R), C^{\infty}\left(S^{1}, S^{1}\right)$, nor their duals can act faithfully on a countable set.

\section{Conclusion.}

List A. simplicial complexes topological manifolds topological manifolds with boundary compact topological manifolds compact topological manifolds with boundary smooth manifolds smooth manifolds with boundary compact smooth manifolds compact smooth manifolds with boundary pairs in any category above

List B. countable groups countable rings countable dimensional vector spaces over a field $K$ countable dimensional algebras over a field $K$

18. Putting together the results of this paper and [4], we have shown that every functor or cofunctor from a category in List A to a category in List $\mathrm{B}$ is homotopy invariant.

\section{REFERENCES}

1. Peter Freyd, Abelian Categories, Harper and Row, 1964.

2. John W. Keesee, On the homotopy axiom, Ann. of Math. (2) 54 (1951), 247-249.

3. James R. Munkres, Elementary Differential Topology, Princeton University Press, 1966.

4. Brian K. Schmidt, On the homotopy invariance of certain functors, Pacific J. Math., 54 (1974), 245-256.

5. Edwin H. Spanier, Algebraic Topology, McGraw-Hill Book Co., 1966.

Received February 21, 1973. 


\section{PACIFIC JOURNAL OF MATHEMATICS}

\section{EDITORS}

RICHARD ARENS (Managing Editor)

University of California

Los Angeles, California 90024

\section{J. DugundJI}

Department of Mathematics University of Southern California Los Angeles, California 90007

D. Gilbarg and J. Milgram

Stanford University

Stanford, California 94305
University of Washington Seattle, Washington 98105

\section{ASSOCIATE EDITORS}
E. F. BECKENBACH
B. H. NeumanN
F. WolF
K. YoShIDA

\section{SUPPORTING INSTITUTIONS}

\author{
UNIVERSITY OF SOUTHERN CALIFORNIA \\ STANFORD UNIVERSITY \\ UNIVERSITY OF TOKYO \\ UNIVERSITY OF UTAH \\ WASHINGTON STATE UNIVERSITY \\ UNIVERSITY OF WASHINGTON \\ $\stackrel{*}{*} \stackrel{*}{*} \stackrel{*}{ }{ }^{*}$ AMERICAN MATHEMATICAL SOCIETY
}

The Supporting Institutions listed above contribute to the cost of publication of this Journal, but they are not owners or publishers and have no responsibility for its content or policies.

Mathematical papers intended for publication in the Pacific Journal of Mathematics should be in typed form or offset-reproduced, (not dittoed), double spaced with large margins. Underline Greek letters in red, German in green, and script in blue. The first paragraph or two must be capable of being used separately as a synopsis of the entire paper. Items of the bibliography should not be cited there unless absolutely necessary, in which case they must be identified by author and Journal, rather than by item number. Manuscripts, in triplicate, may be sent to any one of the editors. Please classify according to the scheme of Math. Reviews, Index to Vol. 39. All other communications should be addressed to the managing editor, or Elaine Barth, University of California, Los Angeles, California, 90024.

The Pacific Journal of Mathematics expects the author's institution to pay page charges, and reserves the right to delay publication for nonpayment of charges in case of financial emergency.

100 reprints are provided free for each article, only if page charges have been substantially paid. Additional copies may be obtained at cost in multiples of 50 .

The Pacific Journal of Mathematics is issued monthly as of January 1966. Regular subscription rate: $\$ 72.00$ a year (6 Vols., 12 issues). Special rate: $\$ 36.00$ a year to individual members of supporting institutions.

Subscriptions, orders for back numbers, and changes of address should be sent to Pacific Journal of Mathematics, 103 Highland Boulevard, Berkeley, California, 94708.

\section{PUBLISHED BY PACIFIC JOURNAL OF MATHEMATICS, A NON-PROFIT CORPORATION}

Printed at Kokusai Bunken Insatsusha (International Academic Printing Co., Ltd.), 270, 3-chome Totsuka-cho, Shinjuku-ku, Tokyo 160, Japan.

\section{Copyright (C) 1975 by Pacific Journal of Mathematics} Manufactured and first issued in Japan 


\section{Pacific Journal of Mathematics}

\section{Vol. 57, No. $2 \quad$ February, 1975}

Norman Larrabee Alling, On Cauchy's theorem for real algebraic curves with boundary .......

Daniel D. Anderson, A remark on the lattice of ideals of a Prüfer domain ..................

Dennis Neal Barr and Peter D. Miletta, A necessary and sufficient condition for uniqueness of

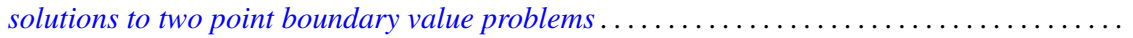

Ladislav Beran, On solvability of generalized orthomodular lattices . . . . . . . . . . ........

L. Carlitz, A three-term relation for some sums related to Dedekind sums . . . . . . . . . .....

Arthur Herbert Copeland, Jr. and Albert Oscar Shar, Images and pre-images of localization

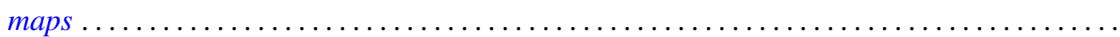

G. G. Dandapat, John L. Hunsucker and Carl Pomerance, Some new results on odd perfect

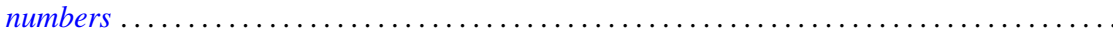

M. Edelstein and L. Keener, Characterizations of infinite-dimensional and nonreflexive

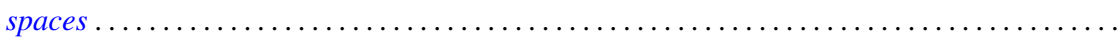

Francis James Flanigan, On Levi factors of derivation algebras and the radical embedding

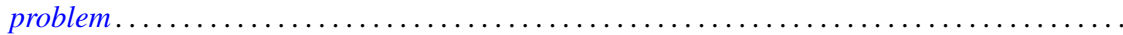

Harvey Friedman, Provable equality in primitive recursive arithmetic with and without

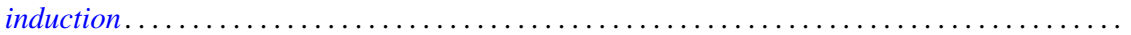

Joseph Braucher Fugate and Lee K. Mohler, The fixed point property for tree-like continua with

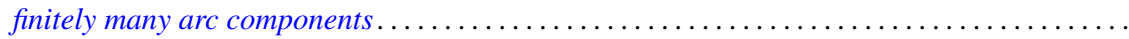

John Norman Ginsburg and Victor Harold Saks, Some applications of ultrafilters in

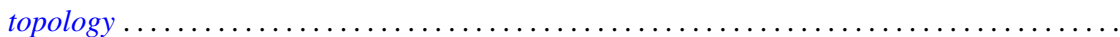

Arjun K. Gupta, Generalisation of a "square" functional equation .....................

Thomas Lee Hayden and Frank Jones Massey, Nonlinear holomorphic semigroups ..........

V. Kannan and Thekkedath Thrivikraman, Lattices of Hausdorff compactifications of a locally

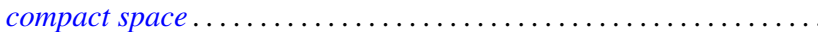

J. E. Kerlin and Wilfred Dennis Pepe, Norm decreasing homomorphisms between group

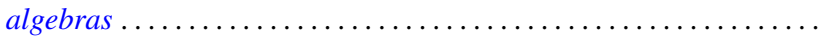

Young K. Kwon, Behavior of $\Phi$-bounded harmonic functions at the Wiener boundary ...

Richard Arthur Levaro, Projective quasi-coherent sheaves of modules .

Chung Lin, Rearranging Fourier transforms on groups...........................

David Lowell Lovelady, An asymptotic analysis of an odd order linear differential equation . . 4475

Jerry Malzan, On groups with a single involution .......................... 481

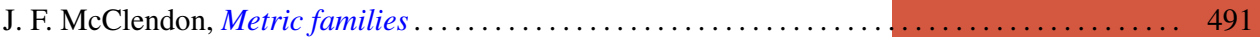

Carl Pomerance, On multiply perfect numbers with a special property .

Mohan S. Putcha and Adil Mohamed Yaqub, Polynomial constraints for finiteness of semisimple rings. .

Calvin R. Putnam, Hyponormal contractions and strong power convergence . . . . . . . . . 531

Douglas Conner Ravenel, Multiplicative operations in $\mathrm{BP} * \mathrm{BP} \ldots \ldots \ldots \ldots \ldots \ldots \ldots \ldots \ldots .539$

Judith Roitman, Attaining the spread at cardinals which are not strong limits . . . . . . . . . 545

Kazuyuki Saitô, Groups of *-automorphisms and invariant maps of von Neumann algebras . . . 553

Brian Kirkwood Schmidt, Homotopy invariance of contravariant functors acting on smooth

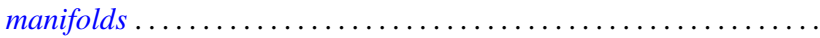

Kenneth Barry Stolarsky, The sum of the distances to $N$ points on a sphere.

Mark Lawrence Teply, Semiprime rings with the singular splitting property.

J. Pelham Thomas, Maximal connected Hausdorff spaces..............

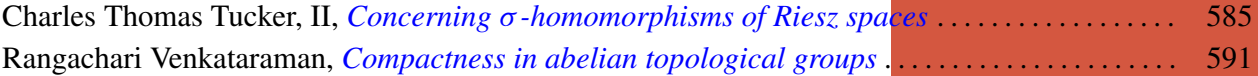

William Charles Waterhouse, Basically bounded functors and flat sheaves . . . . . . . . . . . 597

David Westreich, Bifurcation of operator equations with unbounded linearized part ......... 611

William Robin Zame, Extendibility, boundedness and sequential convergence in spaces of 